\title{
TRUYỀN DẪN CỦA CHÍNH SÁCH TIỀN TỆ ĐẾN TĂNG TRƯỞNG KINH TẾ Ở VIẸT NAM
}

\author{
MONETARY POLICY TRANSMISSION TO \\ ECONOMIC GROWTH IN VIETNAM
}

\section{Hồ Thủy Tiên, Chu Thị Thanh Trang, Hồ Thu Hoài ${ }^{1}$}

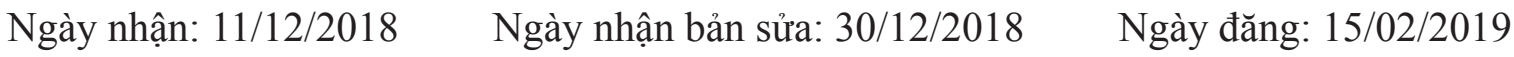

\section{Tóm tắt}

Nghiên cứu truyền dẫn chính sách tiền tệ (CSTT) đến tăng trưởng kinh tế thông qua sử dụng mô hình SVAR, số liệu phân tích được lấy theo quý từ Quý 1/2000 đến Quý 4/2016. Tác giả đã sử dụng kết hợp nhiều phương pháp phân tích để đánh giá cơ chế truyền dẫn từ các biến công cụ và biến trung gian trong cơ chế điều hành CSTT. Kết quả nghiên cứu cho thấy kênh lãi suất là kênh chủ đạo, tác động mạnh đến tăng trưởng kinh tế. Bên cạnh đó, tăng trưởng kinh tế còn phản ứng nhanh trước thay đổi của tỷ giá hối đoái, dự trữ ngoại hối và chỉ số giá chứng khoán. Phân tích phân rã phương sai thông qua các kênh cho thấy tăng trưởng kinh tế có sự khác biệt theo thời gian giữa các kênh. Tù khóa: Tăng trưởng kinh tế, truyền dẫn chính sách tiền tệ, SVAR.

\begin{abstract}
Studying the transmission of monetary policy to economic growth by using the SVAR model, the data is conducted quarterly from Q1/2000 to Q4/2016. The authors uses a combination of analytical methods to evaluate the transmission mechanism from instrument variables and intermediate variables in the monetary policy. The result shows that interest rate channel is the main channel, strongly impact on economic growth. In addition, economic growth has responded quickly to changes in exchange rates, foreign exchange reserves and stock price indices. Analysis of variance decomposition across channels shows that economic growth varies over time between channels.
\end{abstract} Key words: Economic Growth, Monetary Policy Transmission, SVAR.

\section{Giới thiệu}

CSTT là một trong những chính sách vĩ mô quan trọng thúc đẩy kinh tế tăng trưởng, đồng thời kiểm soát lạm phát thông qua các kênh truyền dẫn của CSTT như kênh lãi suất, kênh giá tài sản, kênh tín dụng,... Vì vậy, để có thể vận dụng thành công CSTT qua đó kiểm soát tốt lạm phát thúc đẩy tăng trưởng kinh tế thì các nhà hoạch định chính sách cần hiểu rõ cơ chế truyền dẫn và xem xét các cú sốc của CSTT đến nền kinh tế. Hiểu rõ được tầm quan trọng của CSTT đối với nền kinh tế, trong thời gian

\footnotetext{
${ }^{1}$ Trường Đại Học Tài chính - Marketing
} 
qua, nhiều các nghiên cứu từ hàn lâm đến thực nghiệm đều xem xét và đo lường riêng lẻ hiệu quả của một số kênh truyền dẫn hoặc là tổng hợp các kênh truyền dẫn của CSTT đến nền kinh tế. Hầu hết kết quả của các nghiên cứu này chỉ ra rằng cú sốc của CSTT tác động rõ rệt đến sản lượng và lạm phát với mức độ và thời gian tác động của từng kênh truyền dẫn trong CSTT là khác nhau. Ở Việt Nam đã có một số các nghiên cứu về truyền dẫn CSTT nhưng tập trung nghiên cứu ở kênh lãi suất và tỷ giá, còn các nghiên cứu tổng hợp các kênh truyền dẫn của CSTT đến nền kinh tế còn khá khiêm tốn và hầu như chỉ nghiên cứu cho giai đoạn trước khủng hoảng tài chính toàn cầu 2008. Trong khi đó, Chính phủ Việt Nam những năm gần đây đặc biệt là sau khủng hoảng tài chính 2008 đã điều hành khá hiệu quả CSTT thông qua tổng hòa các kênh truyền dẫn đã kiểm soát tốt lạm phát và duy trì tăng trưởng. Trong đó kênh truyền dẫn nào có vai trò lớn nhất? Và sự thay đổi trong cấu trúc kênh truyền dẫn hiệu quả của CSTT như thế nào? Nhóm nghiên cứu tiếp tục chọn đề tài Truyền dẫn chính sách tiền tệ đến tăng trương kinh tế Việt Nam giai đoạn 2000 - 2016 để giải quyết các vấn đề đặt ra trên đây.

\section{Các nghiên cứu trước đây có liên quan}

Chủ đề về các kênh truyền dẫn CSTT tác động đến tăng trưởng kinh tế của một quốc gia đã thu hút khá đông các nhà nghiên cứu quốc tế thực hiện các nghiên cứu thực nghiệm. Có thể kể đến các nghiên cứu như sau:

Borys và Horváth (2008) nghiên cứu ảnh hưởng của CSTT ở Séc. Sử dụng kỹ thuật mô hình VAR, bài nghiên cứu tìm thấy giá cả và sản lượng suy giảm trong khoảng một năm sau cú sốc thắt chặt CSTT, điều này phù hợp với mục tiêu của ngân hàng Trung ương nước này. Nghiên cứu cũng chỉ ra phản ứng của giá hàng hóa thương mại đối với cú sốc thắt chặt tiền.

Deepak Mohanty (2012) nghiên cứu về kênh truyền dẫn lãi suất ở Ân Độ. Bằng cách sử dụng mô hình SVAR, nghiên cứu tìm thấy bằng chứng chính sách tăng lãi suất có ảnh hưởng trái chiều đến tăng trưởng sản lượng với độ trễ 2 quý và tác động giảm nhẹ lạm phát với độ trễ 3 quý. Thời gian đạt trạng thái cân bằng kéo dài khoảng $8-10$ quý.

Theo John H. Cochrane (2014), phân tích về CSTT với việc cho thấy CSTT có thể tác động đến lãi suất danh nghĩa, và điều chỉnh về lạm phát dự tính. Khi giá cả chậm thay đổi thì CSTT cũng có thể tác động lên lãi suất thực và sản lượng, mặc dù khi lãi suất cao hơn thì kéo theo sản lượng tăng cùng với lạm phát. Vì vậy cần sự phối hợp giữa chính sách tài khóa và CSTT. Và từ đó đưa ra những gợi ý kết hợp chính sách tài khóa và tiền tệ một cách tối ưu trong một khung chính sách mới dựa trên những lý thuyết mới của mô hình Keynesian.

Kitamura và các tác giả (2015), nghiên cứu truyền dẫn lãi suất thị trường sang lãi suất cho vay ở các ngân hàng Nhật bản. Các tác giả phân tích các yếu tố trên bảng cân đối kế toán của ngân hàng truyền dẫn đến lãi suất cho vay của ngân hàng thương mại. Kết quả trên mẫu toàn bộ các ngân hàng cho thấy hệ số truyền dẫn nhỏ đối với các ngân hàng có tỷ lệ cho vay doanh nghiệp vừa và nhỏ lớn hơn; hệ số truyền dẫn cũng thấp với các ngân hàng cho mức độ tập trung thị trường lớn hơn. Nghiên cứu này chưa tìm thấy bằng chứng thống kê ảnh hưởng của 
quy mô ngân hàng và hệ số an toàn vốn đến lãi suất cho vay, trong khi tỷ lệ thanh khoản có tác động cùng chiều với lãi suất cho vay của các ngân hàng. Các đặc điểm nợ của ngân hàng như tỷ lệ vay bằng chứng từ thương mại và trái phiếu công ty trên tổng các khoản vay; tỷ lệ nợ trên vốn chủ sở hữu và hệ số khả năng thanh toán lãi vay có tương quan cùng chiều với lãi suất cho vay của ngân hàng. Trong các nghiên cứu các yếu tố quyết định lãi suất cho vay dựa trên dữ liệu bảng của 122 quốc gia, Perera và Wickramanayake (2016) tìm thấy điều chỉnh lãi suất cho vay liên quan đến các biến kiểm soát kinh tế vĩ mô, hệ thống tài chính ngân hàng cũng như các yếu tố liên quan đến đặc điểm ngân hàng và chất lượng quản trị. Trong các yếu tố, mức độ phát triển của thị trường tài chính, sức mạnh thị trường và minh bạch chính sách của ngân hàng trung ương vẫn là yếu tố kinh tế vĩ mô quan trọng quyết định lãi suất cho vay.

Tại Việt Nam, chủ đề này cũng thu hút sự quan tâm của nhiều nhà nghiên cứu. Trần Ngọc Thơ và Nguyễn Hữu Tuấn (2013) sử dụng mô hình SVAR để xác định độ lớn và thời gian CSTT truyền dẫn đến các biến mục tiêu. Kết quả là có một số puzzle (mô tả hiện tượng trái ngược lý thuyết) tồn tại trong đó có price puzzle. Kênh lãi suất phản ứng trễ với biến lạm phát trong khi lạm phát lại có phản ứng tức thì trước cú sốc tỷ giá hối đoái. Nguyễn Khắc Quốc Bảo \& Nguyễn Hữu Huy Nhựt (2013) tìm thấy hiện tượng bất cân xứng trong truyền dẫn lãi suất ở Việt Nam. Các ngân hàng bị giới hạn về nguồn vốn thì lãi suất cho vay cao đối với nhóm còn lại và truyền dẫn từ lãi suất chính sách sang lãi suất cho vay không rõ ràng. Cao Thị Ý Nhi \& Lê
Thu Giang (2015) sử dụng mô hình SVAR để phân tích kênh truyền dẫn CSTT Việt Nam. Kết quả nghiên cứu cho thấy không có price puzzle nhưng lại tồn tại puzzle khác. Cú sốc tăng cung tiền M2 dẫn đến suy giảm sản lượng trong kỳ tiếp theo, tăng nhẹ trong kỳ thứ 2 và sau đó giữ xu hướng giảm các kỳ kế tiếp. Đối với cú sốc tỷ giá, sản lượng tăng trong kỳ đầu và giảm ngay trong kỳ tiếp theo. Nguyễn Duy Sữu \& Nghiêm Quý Hào (2016) nghiên cứu kênh tín dụng trong truyền dẫn chính sách tiền tệ tại Việt Nam cho kết quả mặc dù có sự liên kết mạnh giữa lãi suất cho vay và lãi suất chiết khấu, nhưng sự truyền tải từ lãi suất cho vay đến tín dụng, từ tín dụng đến tăng trưởng kinh tế và lạm phát còn yếu. Nguyễn Phúc Cảnh và cộng sự (2016), nhóm tác giả thu thập dữ liệu về CSTT và thị trường cổ phiếu Việt Nam giai đoạn 2000 - 2013 để nghiên cứu quá trình truyền dẫn của CSTT qua kênh giá tài sản tài chính bằng mô hình tự hồi quy cấu trúc (SVAR). Kết quả tại Việt Nam, CSTT có truyền dẫn mạnh qua thị trường chứng khoán thông qua cung tiền, trong khi đó lãi suất không có tác động lớn đến thị trường chứng khoán ở cả hai chỉ số VN-Index và HNX-Index và làm cho giá cả thay đổi.

Nhìn chung các nghiên cứu trong nước và nước ngoài đều đưa ra các kết quả khác nhau về hiệu lực của các kênh truyền dẫn CSTT đến nền kinh tế của từng quốc gia do đặc thù khác nhau và các giai đoạn nghiên cứu khác nhau. Với đặc thù Việt Nam là một quốc gia có nền kinh tế đang chuyển đổi với qui mô nền kinh tế nhỏ nhưng độ mở lại lớn vì vậy các cú sốc từ bên ngoài chắc chắn có sự tác động rất lớn đến CSTT trong nước vì vậy sẽ không tránh khỏi 
hiệu lực truyền dẫn của CSTT đến nền kinh tế, đặc biệt là giai đoạn những năm gần đây. Cho nên việc thực hiện đề tài trong giai đoạn hiện nay là vẫn cần thiết.

\section{Phương pháp nghiên cứu}

Đề tài sử dụng chuỗi dữ liệu thời gian đại diện cho các kênh truyền dẫn của CSTT và chuỗi dữ liệu thời gian đại diện cho tăng trưởng kinh tế như sản lượng, chỉ số giá cả,... giai đoạn Quý 1 năm 2000 - Quý 4 năm 2016. Sau khi kiểm tra tính dừng, kiểm tra tính đồng liên kết để xác định mối quan hệ trong dài hạn giữa các biến, nhóm nghiên cứu sẽ dùng phương pháp SVAR để đo lường phản ứng của nền kinh tế trước những cú sốc của chính sách tiền tệ trong nước cũng như một số các cú sốc ngoại sinh lan truyền đến các công cụ của CSTT ở Việt Nam như thế nào. Phương pháp SVAR được xem là linh hoạt vì có thể chứa nhiều mối quan hệ giữa các biến số kinh tế vĩ mô dựa trên lý thuyết kinh tế và lần lượt cho phép chúng ta xác định được những cú sốc (shock) tiền tệ trực giao.

Mô hình bao gồm các biến ngoại sinh đại diện cho yếu tố mở của nền kinh tế Việt Nam bao gồm: Biến tăng trưởng kinh tế Mỹ (GDPU $)_{t}$ là biến đại diện tăng trưởng kinh tế bên ngoài; Biến lãi suất trái phiếu Chính phủ Mỹ $\left(R U_{t}\right)$ đại diện cho thay đổi CSTT bên ngoài ảnh hưởng đến mục tiêu bên trong của nền kinh tế Việt Nam.

Ba nhóm biến nội sinh bao gồm (i) nhóm biến mục tiêu của chính sách bao gồm GDP,

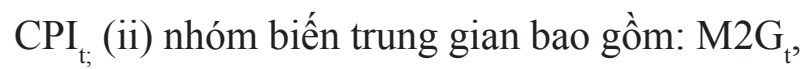
$\mathrm{VNI}_{t}, \mathrm{MIG}_{\mathrm{t}}, \mathrm{EXG}_{\mathrm{t}}, \mathrm{RLB}_{\mathrm{t}}$; (iii) nhóm biến đại diện các kênh truyền dẫn bao gồm: $\operatorname{RDS}_{\mathrm{t}}, \mathrm{EXU}_{\mathrm{t}}$, $\mathrm{RGU}_{\mathrm{t}}$. 


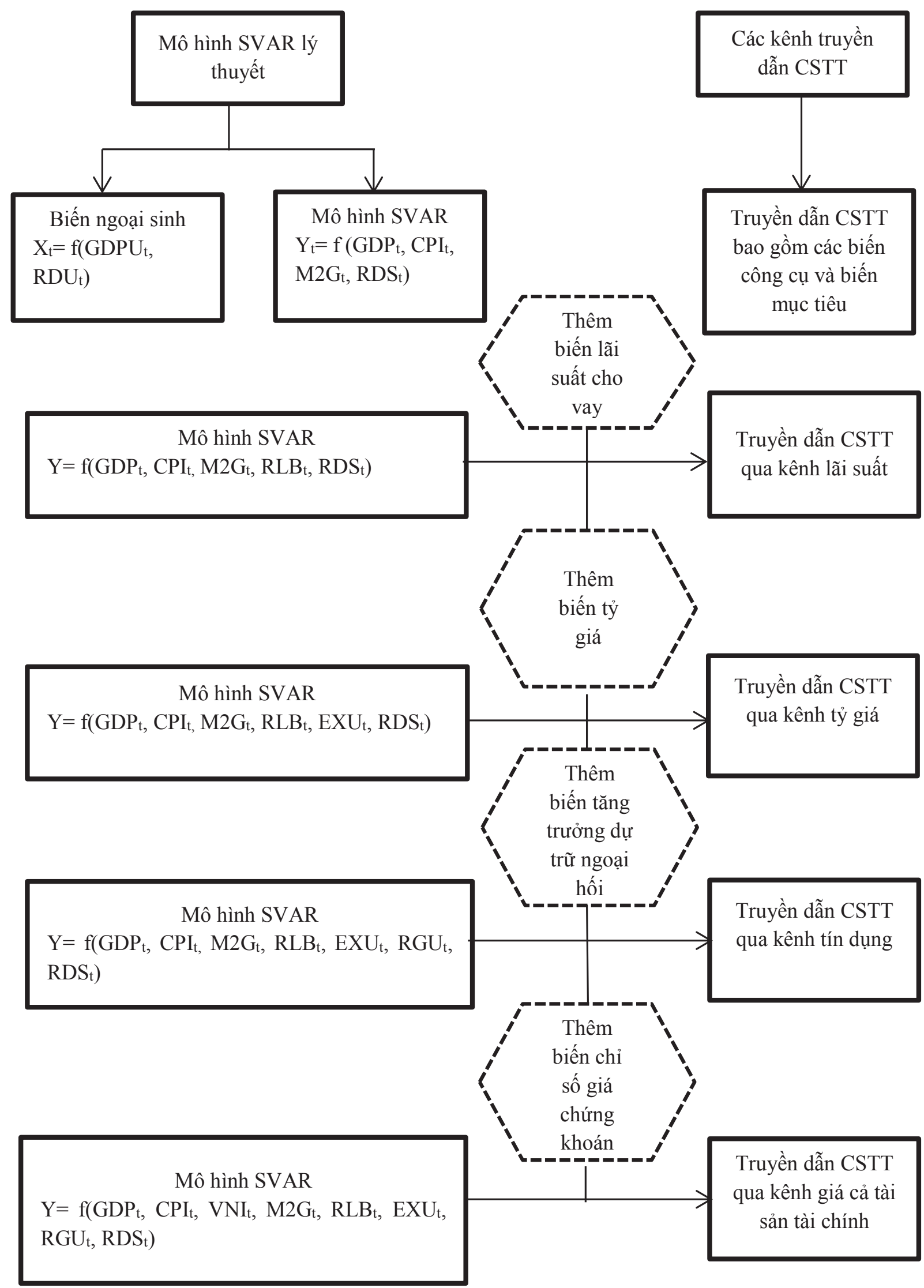

Nguồn: Thiết kế của tác giả

Hình 1. Thiết kế mô hình SVAR đo lường truyền dẫn CSTT tại Việt Nam 
Bảng 1. Tóm tắt các biến sử dụng trong mô hình

\begin{tabular}{|c|c|c|c|}
\hline STT & Biến & Diễn giải & Nguồn \\
\hline 1 & $\mathrm{GDP}_{\mathrm{t}}$ & Tăng trưởng kinh tế Việt Nam & Quỹ Tiền tệ thế giới IMF \\
\hline 2 & $\mathrm{CPI}_{\mathrm{t}}$ & $\begin{array}{l}\text { Lạm phát giá tiêu dùng, đại diện lạm phát } \\
\text { tại Việt Nam }\end{array}$ & $\begin{array}{l}\text { Quỹ Tiền tệ thế giới IMF, Tổng cục } \\
\text { Thống kê Việt Nam }\end{array}$ \\
\hline 3 & $\mathrm{GDPU}_{\mathrm{t}}$ & Tăng trưởng kinh tế Mỹ & Quỹ Tiền tệ thế giới (IMF) \\
\hline 4 & $\mathrm{RDS}_{\mathrm{t}}$ & $\begin{array}{l}\text { Lãi suất tái cấp vốn, đại diện lãi suất chính } \\
\text { sách tại Việt Nam }\end{array}$ & Ngân hàng Nhà nước Việt Nam \\
\hline 5 & $\mathrm{RLB}_{\mathrm{t}}$ & $\begin{array}{l}\text { Lãi suất cho vay bình quân (Bình quân của } \\
\text { NHTM lớn tại Việt Nam: (ACB, VCB, } \\
\text { STB, CTG, ABI) đại diện lãi suất cho vay } \\
\text { trên thị trường tài chính Việt Nam } \\
\end{array}$ & Quỹ Tiền tệ thế giới IMF \\
\hline 6 & $\mathrm{M} 2 \mathrm{G}_{\mathrm{t}}$ & Tăng trưởng cung tiền M2 & $\begin{array}{l}\text { Quỹ Tiền tệ thế giới IMF, Ngân hàng } \\
\text { Châu Á Thái Bình Dương (ADB) }\end{array}$ \\
\hline 7 & $\mathrm{EXU}_{\mathrm{t}}$ & Tỷ giá hối đoái USD/VND & Ngân hàng Nhà nước Việt Nam \\
\hline 8 & $\mathrm{RGU}_{\mathrm{t}}$ & Tăng trưởng dự trữ ngoại hối & Quỹ Tiền tệ thế giới IMF \\
\hline 9 & $\mathrm{VNI}_{\mathrm{t}}$ & Chỉ số giá chứng khoán Việt Nam & $\begin{array}{l}\text { Sở Giao dịch chứng khoán TP.HCM } \\
\text { (HOSE) }\end{array}$ \\
\hline 10 & $\mathrm{MIG}_{\mathrm{t}}$ & Tăng trưởng nhập khẩu & Quỹ Tiền tệ thế giới (IMF) \\
\hline 11 & $\mathrm{EXG}_{\mathrm{t}}$ & Tăng trưởng xuất khẩu & Quỹ Tiền tệ thế giới (IMF) \\
\hline 12 & $\mathrm{RDU}_{\mathrm{t}}$ & $\begin{array}{l}\text { Lãi suất trái phiếu Chính phủ Mỹ, đại diện } \\
\text { lãi suất chính sách bên ngoài nền kinh tế }\end{array}$ & Quỹ Tiền tệ thế giới (IMF) \\
\hline
\end{tabular}

Nguồn: Tác giả tổng hợp

\section{Kết quả nghiên cứu}

Đầu tiên, nhóm tác giả thực hiện các bước kiểm định chuỗi dữ liệu thời gian lần lượt như sau:

Kiểm định tính dừng: Tác giả sử dụng kiểm định Dickey - Fuller để kiểm định nghiệm đơn vị cho thấy 6 chuỗi dữ liệu dừng ở chuỗi gốc và 7 chuỗi dữ liệu dừng ở sai phân bậc 1 . Hầu hết các chuỗi dữ liệu đều có mức thống kê $1 \%$. Với kết quả này, các chuỗi dữ liệu hoàn toàn phù hợp với ràng buộc khi ứng dụng mô hình SVAR.

Xác định độ trễ tối ưu: Việc xác định độ trễ tối ưu rất quan trọng trong việc nghiên cứu về sự tác động CSTT truyền dẫn. Tác giả xác định độ trễ tối ưu được đánh giá nhiều nhất dựa trên các tiêu chuẩn $\mathrm{LR}, \mathrm{FPE}, \mathrm{AIC}, \mathrm{SC}$ và $\mathrm{HQ}$. Kết quả cho thấy độ trễ tối ứu được lựa chọn là 4 quý.

Kiểm định đồng liên kết: nhóm kiểm định đồng liên kết bằng kiểm định Johansen (Johansen Cointergation Test) nhằm xác định có hay không mối quan hệ dài hạn giữa các biến. Kết quả kiểm định cho thấy tồn tại 8 đồng liên kết với mức ý nghĩa $5 \%$. Dựa vào kết quả trên, các biến có mối quan hệ dài hạn và tác động mạnh với nhau. 
Kiểm định sự phù hợp của mô hình: Kết quả cho thấy các nghiệm đều nằm trong vòng tròn đơn vị. Nghĩa là, kết quả đáp ứng được điều kiện ổn định của mô hình. Vì thế, kết quả phân tích đưa ra đảm bảo độ tin cậy của mô hình nghiên cứu.

Bảng 2. Kết quả hồi quy

\begin{tabular}{|l|r|r|r|}
\hline \multirow{2}{*}{ Variables independent } & \multicolumn{3}{|c|}{ Variable dependent (GDP) } \\
\cline { 2 - 4 } & Coefficient & t-statistics & \multicolumn{1}{c|}{ Probability } \\
\hline GDPU (-1) & 0.427751 & 2.54586 & $5 \%$ \\
\hline RDS (-3) & -0.57102 & -2.86346 & $5 \%$ \\
\hline EXU (-1) & -0.00418 & -5.31286 & $10 \%$ \\
\hline RGU (-2) & -0.018651 & 2.53697 & $5 \%$ \\
\hline VNI (-3) & 0.039182 & 2.30407 & $5 \%$ \\
\hline C & 12.36211 & 3.29503 & $5 \%$ \\
\hline R-squared & 0.856585 & Log likelihood & -56.5653 \\
\hline Adj. R-squared & 0.741854 & Akaike AIC & 2.673915 \\
\hline Sum sq. resids & 21.94789 & Schwarz SC & 3.652159 \\
\hline S.E. equation & 0.791885 & Mean dependent & 6.684747 \\
\hline F-statistic & 7.465988 & S.D. dependent & 1.558581 \\
\hline
\end{tabular}

Nguồn: Tác giả tổng hợp

Với kết quả hồi quy có được ta thấy GDP chịu tác động thuận từ tăng trưởng kinh tế Mỹ với độ trễ 1 quý, có nghĩa khi nền kinh tế Mỹ tăng trưởng sẽ mang đến thông tin tốt cho nền kinh tế Việt Nam. Tác động từ các chính sách hỗ trợ từ Mỹ sẽ làm cho nền kinh tế Việt Nam tăng trưởng.

Ngoài ra, lãi suất tái cấp vốn (RDS) tăng tác động tiêu cực đến nền kinh tế, làm cho tăng trưởng kinh tế giảm với độ trễ của chính sách là 3 quý. Khi lãi suất tăng, phản ứng ngay lập tức là cầu vốn sẽ giảm. Nhưng một thời gian sau, lãi suất tăng tác động tiêu cực đến nền kinh tế thông qua áp lực lên chi phí vốn các doanh nghiệp, làm cho chi phí đầu vào tăng dẫn đến hiệu quả kinh doanh giảm. Hơn nữa, khi lãi suất tái cấp vốn tăng kéo theo lãi vay các công cụ tài chính khác tăng, do đó làm tăng chi phí đầu vào của doanh nghiệp, doanh nghiệp hạn chế vay vốn để sản xuất kinh doanh và cuối cùng là làm cho sản lượng giảm trong ngắn lẫn dài hạn.

Tỷ giá hối đoái (EXU), dự trũ̃ ngoại hối (RGU) tăng tác động nghịch với tăng trưởng kinh tế và tác động trễ lần lượt 1 quý, 2 quý. Nền kinh tế Việt Nam trong thời gian qua luôn trong tình trạng nhập siêu, chính vì vậy mà khi tỷ giá tăng tác động mạnh đến chi phí nhập khẩu. Chi phí nhập khẩu tăng làm cho chi phí đầu vào của hoạt động sản xuất tăng và cuối cùng tác động tiêu cực đến tăng trưởng. Đồng thời, mặc dù dự trữ ngoại hối cao sẽ gia tăng mức an toàn vốn quốc gia cao, tuy nhiên trong bối cảnh phát triển kinh tế thị trường, nền kinh tế rất cần một lượng vốn dồi dào để phát triển. Chính vì vậy việc gia tăng dự trữ cao trong giai đoạn này sẽ tác động không tốt đến nền kinh tế, nhất là khi mà đất nước còn phụ thuộc nhiều vào nguồn vốn vay bên ngoài. 
Chỉ số giá chứng khoán (VNI) tăng góp phần làm cho tăng trưởng kinh tế tăng. Có thể nói thị trường chứng khoán Việt Nam những năm gần đây đóng góp rất lớn cho nền kinh tế. Bên cạnh là kênh huy động vốn hiệu quả thì thị trường chứng khoán còn là kênh cung cấp thông tin hữu ích cho nền kinh tế. Hơn nữa, thị trường chứng khoán là nơi tựu trung những công ty có quy mô vốn lớn, do vậy thị trường tăng trưởng đồng nghĩa với việc các doanh nghiệp ngày càng gia tăng về quy mô lẫn chất lượng.

Tiếp theo, nhóm tác giả sẽ xem xét phản ứng của tăng trưởng kinh tế thông qua các kênh truyền dẫn khác nhau bằng phân tích phản ứng sốc và phân rã phương sai.

\section{Kênh lãi suất}

Response to Cholesky One S.D. Innovations \pm 2 S.E.

Response of GDP SA to RLB SA

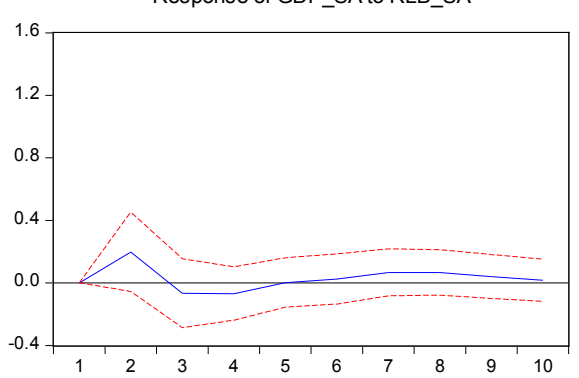

Response of RLB_SA to RLB_SA

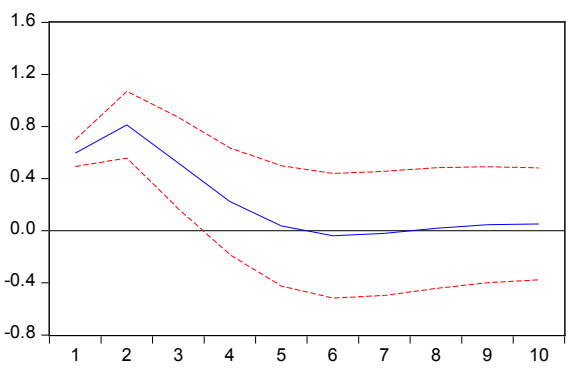

Response to Cholesky One S.D. Innovations \pm 2 S.E.

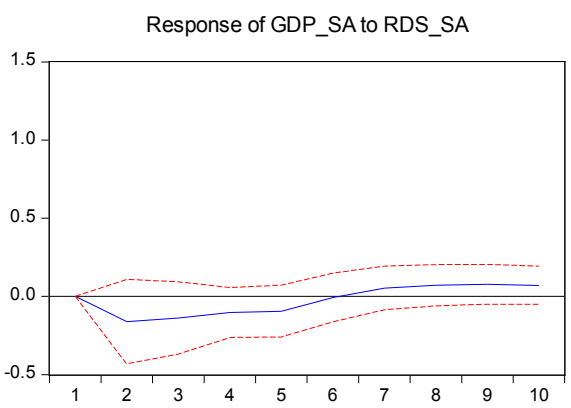

Response of RDS_SA to RDS_SA

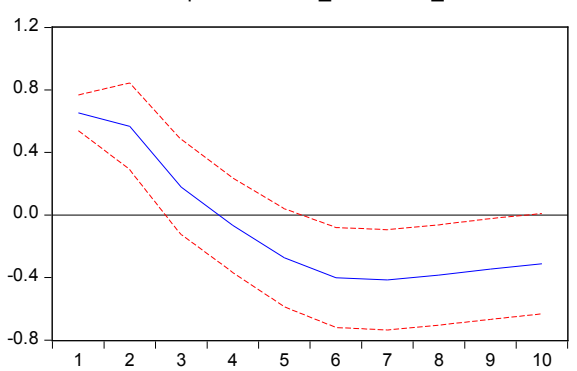

Response of GDP SA to GDP SA

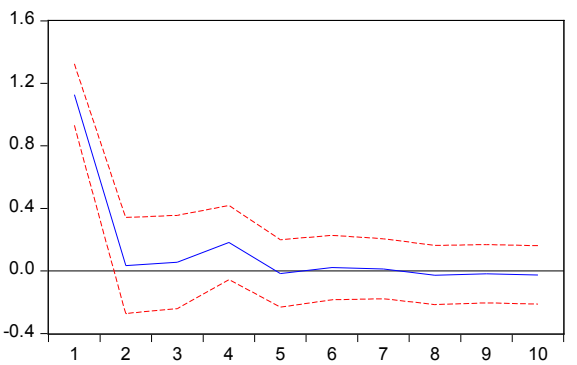

Response of RLB_SA to GDP_SA

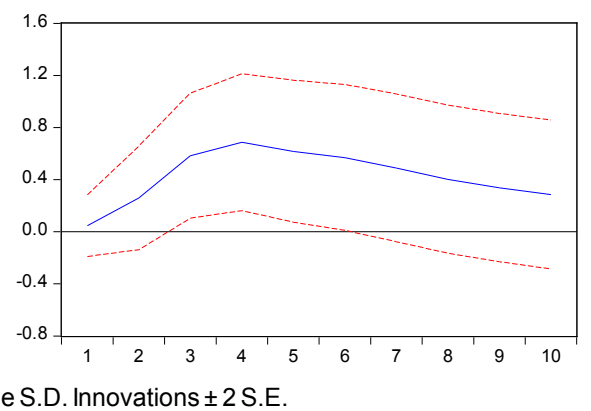

Response of GDP_SA to GDP_SA

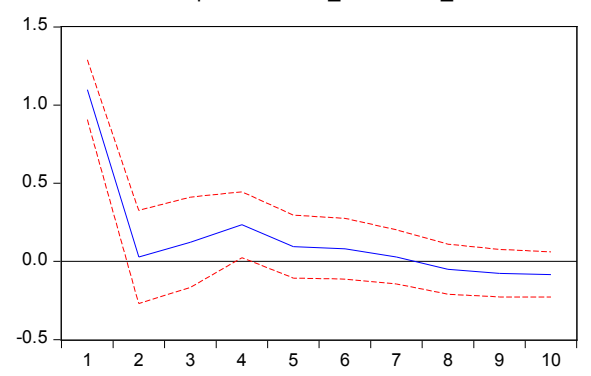

Response of RDS_SA to GDP_SA

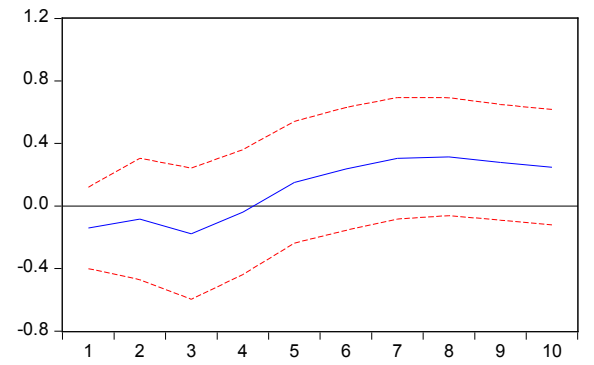

Nguồn: Số liệu được thống kê tù tác giả.

Hình 2. Phản ứng của tăng trưởng trước thay đổi của lãi suất 
Phản ứng của tăng trưởng kinh tế trước cú sốc lãi suất tiền gửi bắt đầu tăng nhẹ từ Quý 1 đến Quý 2. Sau đó tăng trưởng đột ngột giảm mạnh hơn 4\% và dần ổn định ở các quý sau đó. Kết quả này hoàn toàn phù hợp với lý thuyết CSTT. Nghĩa là, khi ngân hàng Nhà nước tăng lãi suất tiền gửi, nhà đầu tư có xu hướng chọn việc gửi tiền vào ngân hàng thay vì đầu tư vào những khoản rủi ro khác. Thế nhưng, CSTT thắt chặt bằng lãi suất tiền gửi chỉ có tác dụng trong ngắn hạn. Mặt khác, khi tăng lãi suất tái cấp vốn ngân hàng Nhà nước, nền kinh tế Việt Nam phản ứng giảm nhẹ ở những quý đầu và đảo chiều với ghi nhận tại đỉnh hơn 3\% ở Quý 3. Từ sau Quý 3, tăng trưởng kinh tế phản ứng chậm lại và không còn bị tác động bởi lãi suất cho vay bình quân từ Quý 4 trở đi. Tóm lại, tăng trưởng kinh tế chỉ phản ứng trong ngắn hạn trong truyền dẫn kênh giá lãi suất.
Tuy nhiên, cơ chế truyền dẫn từ lãi suất chính sách đến lãi suất thị trường và cuối cùng là đến tăng trưởng kinh tế cần xem xét nhiều hơn. Phân rã phương sai của lãi suất tái cấp vốn, tăng trưởng kinh tế bắt đầu chịu tác động của cú sốc lãi suất tái cấp vốn và Quý thứ 2 và mạnh nhất là 9.6\% tại Quý 8 . Đối với lãi suất cho vay bình quân, tăng trưởng kinh tế phản ứng nhanh hơn, nhưng không mạnh bằng lãi suất tái cấp vốn. Phản ứng bắt đầu vào Quý thứ 2 và đạt mức độ cao nhất vào Quý 3 là 4.7\%. Kết quả này cho thấy giữa lãi suất tái cấp vốn và lãi suất cho vay, thì tăng trưởng kinh tế còn phụ thuộc vào việc điều hành lãi suất chính sách, trong đó lãi suất tái cấp vốn đóng vai trò quan trọng trong việc điều tiết lãi suất của nền kinh tế.

\section{Kênh tỷ giá}
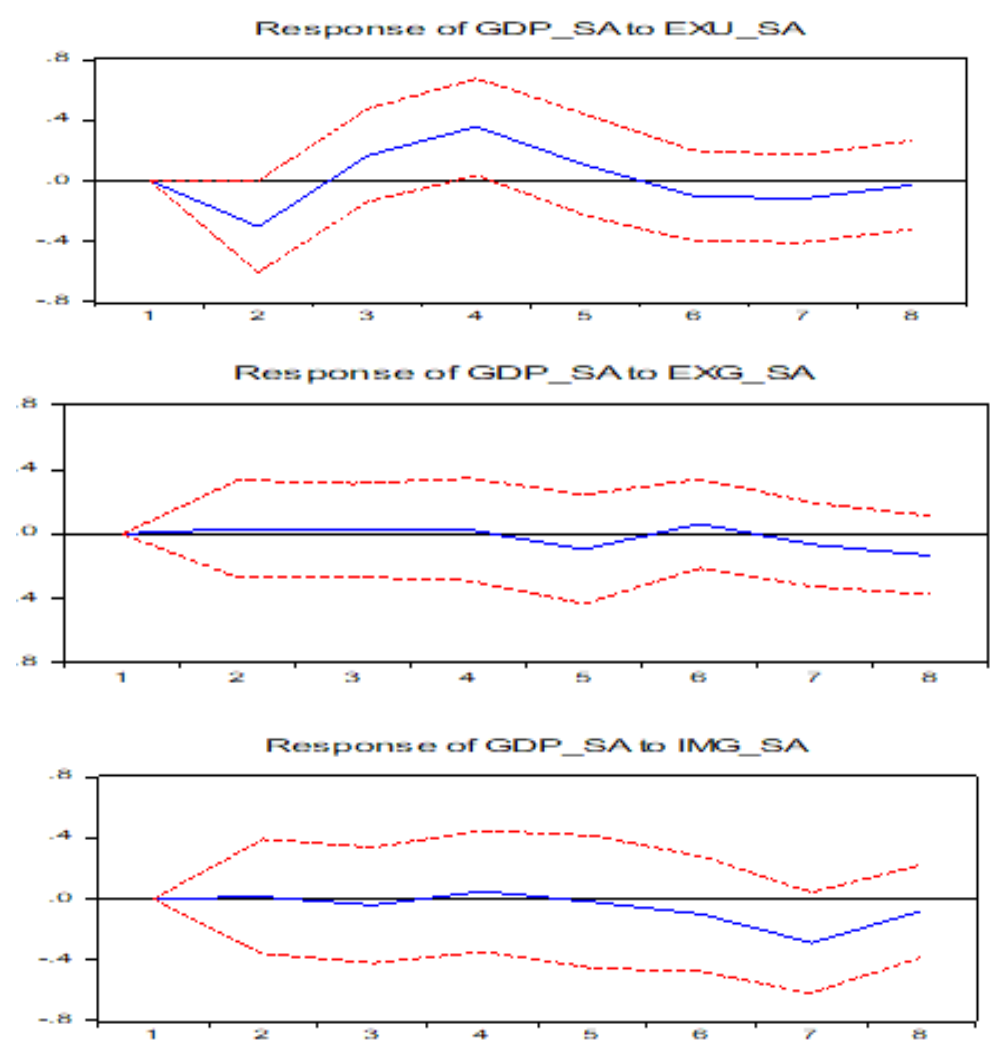

Nguồn: Số liệu được thống kê tù tác giả.

Hình 3. Phản ứng của tăng trưởng trước thay đổi của tỷ giá 
Tăng trưởng kinh tế Việt Nam có biến động mạnh trước cú sốc của tỷ giá. Cụ thể, tăng trưởng kinh tế giảm khoảng $3 \%$ ở 2 quý đầu và đột ngột tăng mạnh từ Quý 2 đến hơn 7\% và bắt đầu điều chỉnh phản ứng trước cú sốc tỷ giá đến hết cuối kỳ 8.

Kết quả của phân rã phương sai cho thấy, tỷ giá ảnh hưởng mạnh nhất đến tăng trưởng kinh tế so với các cú sốc vĩ mô khác, với 7.596\% ở Quý 3. Mặt khác cú sốc tăng trưởng nhập khẩu tác động đến tăng trưởng kinh tế Việt Nam

mạnh hơn cú sốc tăng trưởng xuất khẩu với (7.08\% ở quý 20 của nhập khẩu so với 3.105\% ở Quý 2 của xuất khẩu). Mặc dù nền kinh tế Việt Nam đặt mục tiêu vào xuất khẩu, tuy nhiên tác giả tìm thấy được sự tác động của cú sốc tăng trưởng nhập khẩu ảnh hưởng đến tăng trưởng mạnh hơn cú sốc tăng trưởng xuất khẩu. Vì vậy, kết quả dẫn tới tỷ giá có xu hướng thay đổi theo chu kỳ kinh doanh khiến cho khó có thể tìm được thông tin.

\section{Kênh tín dụng}

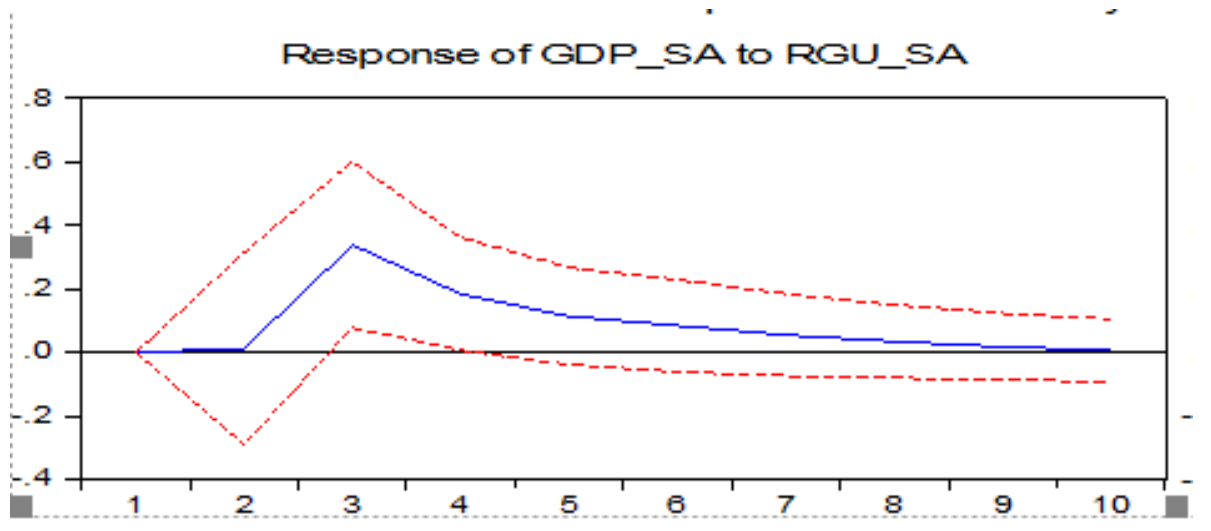

Hình 4. Phản ứng của tăng trưởng trước thay đổi dự trữ ngoại hối

Nguồn: Số liệu được thống kê tù tác giả.

Tăng trưởng kinh tế Việt Nam phản ứng mạnh nhất trước cú sốc tăng trưởng tổng dự trữ ngoại tệ trong kênh tín dụng so với các kênh truyền dẫn khác. Sự tăng trưởng kinh tế phản ứng ngay từ những quý đầu tiên và đạt $4 \%$ ở Quý 3, sau đó trở về mức cân bằng ở Quý 5 . Từ những quý sau, cú sốc tăng trưởng tổng dự trữ ngoại tệ tác động vừa phải đến tăng trưởng kinh tế Việt Nam. Dự trữ ngoại tệ đóng vai trò rất quan trọng trong việc điều tiết nguồn ngoại tệ. Nhưng nếu dự trữ quá mức sẽ tác động đến tiêu cực đến nền kinh tế.

Kết quả phân rã phương sai cho thấy tăng trưởng kinh tế Việt Nam phản ứng mạnh nhất dưới cú sốc tăng trưởng tổng dự trữ ngoại tệ với $5.9 \%$ ở Quý 4. Mặc dù mức độ phản ứng của tăng trưởng trước thay đổi của dự trữ ngoại hối còn thấp so với lãi suất và tỷ giá. Nhưng xét về thời gian phản ứng thì tăng trưởng kinh tế phản ứng trước thay đổi của dự trữ ngoại hối nhanh hơn so với lãi suất (4.7\% so với 3.2\% tại quí thứ 3). Kết quả này có thể giải thích rằng, dự trữ ngoại hối tác động trực tiếp đến nguồn cung ứng vốn trong nền kinh tế, nhưng vì quy mô dự trữ không cao do vậy mà tác động đến tăng trưởng kinh tế thấp. Trong khi lãi suất tác động hầu hết các thành phần của nền kinh tế. 


\section{Kênh giá cả tài sản}

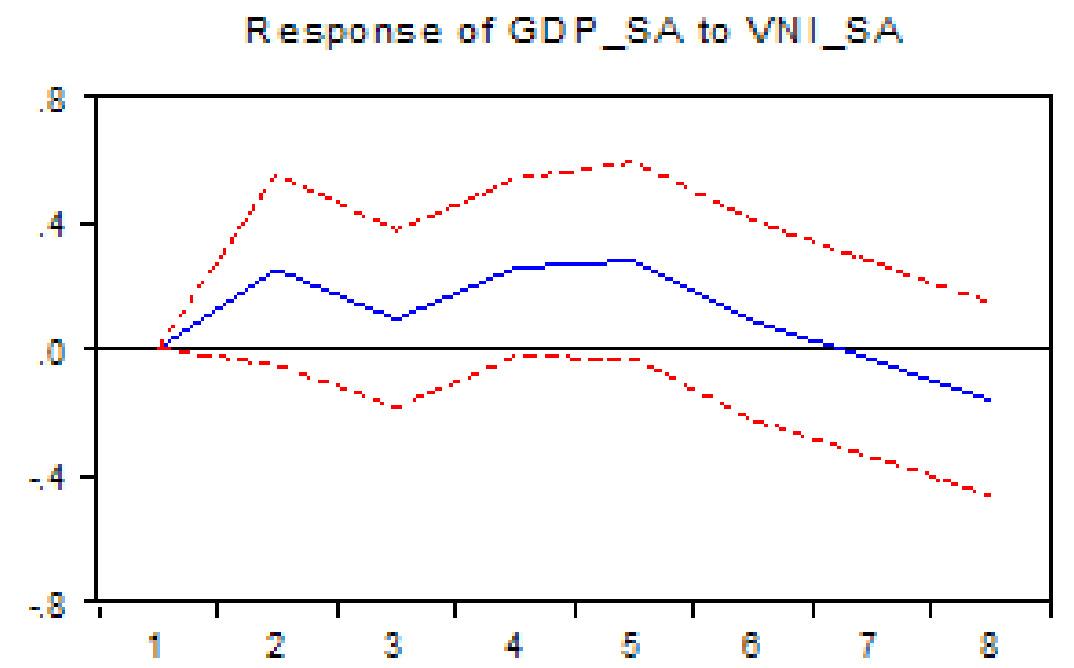

\section{Hình 5. Phản ứng của tăng trưởng trước thay đổi của chỉ số chứng khoán}

Nguồn: Số liệu được thống kê tù̀ tác giả.

Chỉ số chứng khoán VN-Index được xem biến đại diện chính cho kênh giá tài sản. Tăng trưởng kinh tế phản ứng sốc trước thay đổi của chỉ số giá chứng khoán, tăng nhẹ đến gần $2 \%$ ở Quý 2 và chạm đỉnh ở Quý 5 ở khoảng $6 \%$. Sau đó cú sốc VNI khiến tăng trưởng kinh tế giảm mạnh hơn 3.5\%. Kết quả đưa ra trái ngược với lý thuyết Tobin và mô hình chu kỳ sống của Modigliani. Thông thường, thị trường chứng khoán có vai trò quan trọng trong việc dự báo khả năng tăng trưởng của nền kinh tế. Tuy nhiên, kết quả đưa ra có sự biến động trong 1 khoảng thời gian dài. Điều đó có nghĩa, thị trường chứng khoán Việt Nam vẫn còn là thị trường dạng yếu và chưa có thể đánh giá tăng trưởng kinh tế một cách hiệu quả nhất. Thị trường chứng khoán đóng vai trò là kênh huy động vốn dài hạn, tuy nhiên, thực tế cho thấy thị trường chứng khoán Việt Nam chưa phát huy tốt về điều này. Hay nói cách khác TTCK Việt Nam thời gian qua chỉ đáp ứng nhu cầu đầu cơ ngắn hạn, điều này cho thấy thị trường chứng khoán Việt Nam vẫn chưa hiệu quả. Mặc dù thị trường vẫn cung cấp thông tin cho nền kinh tế, tuy nhiên thông tin đa chiều, chưa đáng tin cậy, hiện tượng thao túng thị trường vẫn diễn ra. Chính những điều trên làm cho chỉ số giá chứng khoán thay đổi thất thường, gây thiệt hại cho nhà đầu tư nhỏ lẻ và và làm cho nền kinh tế khó dự đoán.

\section{Kết luận}

Kết quả nghiên cứu là bằng chứng giúp cho việc định hướng chính sách, dự báo tăng trưởng nền kinh tế trong thời gian tới. Từ đó, giúp cho nhà làm chính sách cảnh giác với những biến động bên ngoài trong việc đưa ra cơ chế điều hành phù hợp.

Đối với các kênh truyền dẫn, kênh lãi suất vẫn là kênh chủ đạo, tác động mạnh đến tăng trưởng kinh tế. Không giống như những kênh khác, kênh lãi suất tác động trực tiếp và rõ ràng nhất, trong đó lãi suất tái cấp vốn của ngân hàng Nhà nước là biến tác động rõ ràng đến tăng trưởng. Cơ chế truyền dẫn thông qua lãi suất truyền dẫn nhanh đến các biến vĩ mô như cung 
tiền, tỷ giá, chỉ số giá chứng khoán, từ đó tác động trở lại đến tăng trưởng kinh tế, kết quả trên đồng thuận với Deepak Mohanty (2012), Nguyễn Khắc Quốc Bảo (2013).

Phân tích phản ứng sốc của tăng trưởng kinh tế trước thay đổi của các biến đại diện các kênh trong cơ chế truyền dẫn cho thấy thông qua kênh lãi suất, tăng trưởng kinh tế phản ứng nhanh trước lãi suất tái cấp vốn, nhưng lại phản ứng chậm trước lãi suất cho vay bình quân. Thông qua kênh tỷ giá cho thấy tăng trưởng kinh tế phản ứng nhanh trước tỷ giá, nhưng lại phản ứng chậm trước xuất khẩu và nhập khẩu. Thông qua kênh tín dụng cho thấy tăng trưởng phản ứng nhanh, mạnh trước thay đổi dự trữ ngoại hối. Thông qua kênh giá cả tài sản, tăng trưởng kinh tế phản ứng nhanh trước thay đổi của chỉ số giá chứng khoán theo hướng tích cực.

Phân tích phân rã phương sai thông qua các kênh cho thấy tăng trưởng kinh tế có sự khác biệt theo thời gian giữa các kênh. Thông qua kênh lãi suất, lãi suất tái cấp vốn vẫn là biến tác động mạnh đến tăng trưởng trong ngắn hạn lẫn dài hạn. Bên cạnh đó, lãi suất cho vay bình quân vẫn đóng góp đáng kể đến tăng trưởng trong ngắn hạn. Thông qua kênh tỷ giá, tỷ giá vẫn là biến giải thích tăng trưởng kinh tế mạnh nhất và đạt mức độ lớn nhất vào quý thứ 3 . Kênh tín dụng qua việc phát hiện mới biến dự trữ ngoại hối tác động đến tăng trưởng kinh tế trong ngắn hạn lẫn dài hạn.

\section{Tài liệu tham khảo}

\section{Tiếng Việt}

Cao Thị Ý Nhi, Lê Thu Giang (2015), Ứng dụng mô hình SVAR nghiên cứu kênh truyền dẫn tiền tệ và gợi ý chính sách tiền tệ ở Việt Nam, Tạp chí kinh tế \& phát triển, Đại học kinh tế Quốc dân, 2015.

Nguyễn Khắc Quốc Bảo (2013). Truyền dẫn chính sách tiền tệ Tại VN. Tạp chi Phát triển \& hội nhập, 13(23),15-22.

Trần Ngọc Thơ \& cộng sự (2013). Cơ chế truyền dẫn chính sách tiền tệ ở VN. Tạp chi Phát triển \& hội nhập, 10(20), 8-16.

\section{Tiếng Anh}

Borys, M. M., \& Horvath, R. (2008). The Effects of Monetary Policy in the Czech Republic: An Empirical Study $\mu$, William Davidson Institute, Working Paper No. 922.

Cochrane, J. H. (2014). Monetary policy with interest on reserves. Journal of Economic Dynamics and Control, 49, 74-108.

Deepak Mohanty. (2012). Evidence of Interest Rate Channel of Monetary Policy Transmission in India. RBI working paper

Kitamura, T., Muto, I., \& Takei, I. (2015). How do Japanese banks set loan interest rates?: Estimating pass-through using bank-level data (No. 15-E-6). Bank of Japan.

Perera, A., \& Wickramanayake, J. (2016). Determinants of commercial bank retail interest rate adjustments: Evidence from a panel data model. Journal of International Financial Markets, Institutions and Money, 45, 1-20. 